\title{
LA INFLUENCIA \\ DE LA CONSTITUCIÓN DE 1812 EN EL CONTROL DE LAS CUENTAS PÚBLICAS
}

LUIS VACAS GARCÍA-ALÓS 
SUMARIO

1. LOS ANTECEDENTES DEL TRIBUNAL DE CUENTAS Y LA REGULACIÓN CONSTITUCIONAL DEL CONTROL DE LAS CUENTAS PÚBLICAS EN LA CONSTITUCIÓN DE 1812. 2. ASPECTOS SUBJETIVOS DEL CONTROL CONTABLE EN EL TEXTO CONSTITUCIONAL DE CÁDIZ. 3. ASPECTOS OBJETIVOS DEL CONTROL DE LAS CUENTAS PÚBLICAS DESDE LA NORMA CONSTITUCIONAL GADITANA. 4. ASPECTOS FORMALES DEL CONTROL DEL GASTO PÚBLICO DESDE 1812. 5. CONSIDERACIONES FINALES. 6. BIBLIOGRAFÍA BÁSICA SOBRE EL TRIBUNAL DE CUENTAS. 


\title{
LA INFLUENCIA \\ DE LA CONSTITUCIÓN DE 1812 EN EL CONTROL DE LAS CUENTAS PÚBLICAS
}

POR

\author{
LUIS VACAS GARCÍA-ALÓS
}

Magistrado del Gabinete Técnico del Tribunal Supremo

Ex Director Técnico de la Sección de Enjuiciamiento del Tribunal de Cuentas

\section{LOS ANTECEDENTES DEL TRIBUNAL DE CUENTAS Y LA REGULACIÓN CONSTITUCIONAL DEL CONTROL DE LAS CUENTAS PÚBLICAS EN LA CONSTITUCIÓN DE 1812}

La Constitución de Cádiz de 1812, con la denominación «de las contribuciones», dedicó el Título VII a regular los aspectos más relevantes de la Hacienda pública. Un total de dieciocho preceptos — artículos 338 a 355- se ocuparon de cuestiones tales como el establecimiento de dichas contribuciones por las Cortes, su periodicidad anual, las clases de contribuciones, su inclusión en el presupuesto y la fijación y distribución de las mismas. Juntamente con las referidas previsiones, los mencionados preceptos se ocupaban también, en el plano orgánico, del Secretario del despacho de Hacienda, así como de la Tesorería general y las Tesorerías provinciales.

En el apuntado aspecto orgánico, el artículo 350 se refería a la Contaduría Mayor de Cuentas. Este precepto se expresaba en los siguientes términos:

«Para el examen de todas las cuentas de caudales públicos habrá una Contaduría Mayor de Cuentas, que se organizará por una ley especial.» 
Se da la circunstancia de que esta ley especial de la Contaduría Mayor de Cuentas no se promulgó hasta el año 1819, siendo posteriormente complementada por la Instrucción de 30 de junio de 1820, por la Real Cédula de 10 de noviembre de 1828 y por los Reales Decretos de 23 de mayo de 1845 y 24 de octubre de 1849, así como por las Leyes de 20 de febrero de 1850 y 19 de mayo de 1870. Esta última disposición legal estableció que la propia Contaduría Mayor de Cuentas quedaría a cargo del Ministerio de Hacienda. A partir del 29 de mayo de 1873, se refundieron sus funciones con la institución del Tribunal de Cuentas, que fue objeto de regulación, entre otras, en las Leyes de 25 de junio de 1870, 27 de diciembre de 1878 y 1 de julio de 1911, así como en el Reglamento de 3 de octubre de ese mismo año.

Además de la citada Ley de 1819, que promulgó la Contaduría Mayor de Cuentas, las principales normas de contenido económico que desarrollaron los artículos 338 a 355 de la Constitución de 1812 fueron el Decreto de las Cortes de 12 de abril de 1813, que suprimió la Superintendencia de Rentas, creó la Dirección General de Hacienda y contribuyó decisivamente a la aprobación de un Reglamento para la Tesorería General de Hacienda y la creación de unos denominados «Juzgados de Hacienda».

Con posterioridad a 1812, otras Constituciones se ocuparon también de la Contaduría Mayor de Cuentas y, más recientemente, del Tribunal de Cuentas: es el caso de los artículos 42 de la Constitución de 1856, 58 de la Constitución de 1869, 22 de la Constitución de 1876, 120 de la Constitución de 1931 y 136 y 153 de la vigente Constitución de 1978.

Por lo demás, los antecedentes más remotos anteriores a 1812 de la Contaduría Mayor y del Tribunal de Cuentas se encuentran en Ordenanzas tan antiguas como la de 1283, que creó la figura del Maestro Racional, que controlaba las finanzas y el patrimonio de la Corona de Aragón; las de las Cortes de Palencia de 1313, que establecieron la institución del Tomador de Cuentas; la Ordenanza de 1365, que creó la Cámara de Comptos de Navarra; la de 1436, que puso en funcionamiento la Contaduría de Cuentas de Valladolid; y, finalmente, las Ordenanzas otorgadas a la Contaduría Mayor de Cuentas en 2 de julio de 1437, 30 de septiembre de 1442, 10 de julio de 1554 y 26 de octubre de 1602.

Con anterioridad a estas Ordenanzas es difícil encontrar disposiciones que regulasen una función jurisdiccional similar a la del Tribunal de Cuentas. En este sentido puede citarse, con las debidas matizaciones, la llamada «jurisdicción del Intendente», creada en la rúbrica tercera del Cuerpo de los Fueros de Valencia del año 1240, y que fue regulada en los Reales Privilegios de 15 de julio de 1340 y 1 de abril de 1384, así como en las Reales Órdenes de 6 de octubre de 1448 y 13 de abril de 1777. Se trataba de un Magistrado con jurisdicción privativa en todos 
los asuntos concernientes a la Real Hacienda, con preferencia con respecto a los demás Tribunales del Reino en materias de carácter patrimonial relacionadas con la administración del real patrimonio, así como con la sustracción de fondos públicos, y frente a cuyas resoluciones podía interponerse apelación al Real Consejo de Hacienda.

\section{ASPECTOS SUBJETIVOS DEL CONTROL CONTABLE EN EL TEXTO CONSTITUCIONAL DE CÁDIZ}

Mediante Decreto de las Cortes de 22 de marzo de 1811 se inició la formación de los presupuestos, cuya posterior regulación constitucional partió del mandato contenido en los artículos 338 y siguientes de la Constitución de 1812.

A partir de 1819 se crea la Contaduría Mayor de Cuentas que, según se ha dicho anteriormente, tiene como directa cobertura constitucional el artículo 350 del texto de Cádiz. Previamente, el Decreto de 7 de agosto de 1813 aprobó un Reglamento para la referida Contaduría Mayor, que diferenciaba entre un control interno residenciado en las Contadurías de valores y distribución, y un control de tipo jurisdiccional atribuido a la propia Contaduría Mayor de Cuentas.

En el referido año de 1819 se refundieron en la propia Contaduría Mayor las denominadas «Contadurías especiales», tales como las de valores, distribución y millones, que posteriormente, en 1826, volvieron a resurgir.

Por Real Decreto de 23 de mayo de 1845 se hizo una nueva configuración, orgánica y funcional, de la Contaduría Mayor de Cuentas, que perduró hasta el Real Decreto de 24 de octubre de 1849, dotándola de mayor eficacia y operatividad.

El día 20 de febrero de 1850 se promulgó la Ley de Contabilidad, que atribuyó nuevas funciones y medios a la Contaduría Mayor. Dicha Ley supuso, en el aspecto subjetivo, un destacado avance del control contable instaurado con la Constitución gaditana, que, en buena medida, quedaría reforzado con la creación, por medio del Real Decreto de 20 de junio de 1850, de la Dirección de Contabilidad.

En el significativo año de 1870, tan importante en la elaboración y aprobación de leyes que influyeron muy decisivamente en el ulterior devenir de nuestro Ordenamiento jurídico, se promulgó, con fecha 19 de mayo, la Ley de Presupuestos. En virtud de lo dispuesto en esta última Ley, la Contaduría Mayor de Cuentas pasó a depender del Ministerio de Hacienda.

El 23 de mayo de 1873 se unificaron formalmente —antes de esta fecha se produjeron varios precedentes sobre el particular- las funciones de la Conta- 
duría Mayor con las del Tribunal de Cuentas, viéndose así ciertamente reforzado, desde el punto de vista subjetivo, el control contable de las cuentas públicas.

Por consiguiente, la contribución de la Norma constitucional de Cádiz al control de las cuentas públicas fue muy relevante con la elevación, a rango constitucional, de un órgano como la Contaduría Mayor de Cuentas. A ello influyeron decisivamente las siguientes circunstancias:

- La ausencia de un ordenado y unificado sistema impositivo.

- La variedad cuantitativa y cualitativa de los ingresos de la Hacienda pública.

- La dispersión de los gastos públicos y la multiplicidad de los pagos en las cuentas públicas.

- La falta de sistemática y de ordenación contable de los ingresos y de los gastos públicos.

- La carencia de rigor presupuestario y contable en la cobranza y distribución de los fondos públicos.

De hecho, la delimitación del mismo concepto de fondo público, como el de caudal y el de efecto público, no fue cuestión pacífica, teniendo que ser objeto de interpretación por parte de la jurisprudencia, a partir de 1812, en las primeras sentencias del Tribunal Supremo. De ello nos vamos a ocupar seguidamente al tratar de los aspectos objetivos del control de las cuentas públicas.

Por lo demás, con posterioridad a 1813, particularmente en disposiciones legales como las de 26 de mayo de 1835, 2 de agosto de 1886 y, de modo especial, la Ley de Administración y Contabilidad de 1 de julio de 1911, se puso especial énfasis en el sistema de ingreso y distribución centralizada de los fondos del Estado. Y se da la circunstancia de que a esta misma finalidad respondieron las previsiones normativas contenidas en los Reales Decretos de 24 de octubre de 1849, 29 de agosto de 1886 y 12 de agosto de 1903, así como en el artículo 201 del Reglamento del Tribunal de Cuentas, de 3 de octubre de 1911, sobre intervención y custodia de fondos y sobre administración, ingreso y recaudación de tales fondos públicos.

A partir de 1812, el control de las cuentas públicas fue perfilándose progresivamente en torno a un concepto básico y determinante: el de cuentadante, cuyo sustento jurídico quedaría definitivamente plasmado, tras esa evolución que parte en Cádiz con la constitucionalización de la Contaduría Mayor, en los artículos 2, 75 y 76 de la expresada Ley de Administración y Contabilidad de 1911. En este sentido, la figura del cuentadante quedaría ligada a la administración, manejo, custodia y utilización de los distintos bienes, caudales y efectos públicos. 


\section{ASPECTOS OBJETIVOS DEL CONTROL DE LAS CUENTAS PÚBLICAS DESDE LA NORMA CONSTITUCIONAL GADITANA}

Los importes de los ingresos obtenidos por las distintas rentas en los años cronológicamente más próximos a la Constitución de 1812 fueron los siguientes:

- De 1808 a 1812: 142.558 .954 ptas.

- De 1813 a 1819: 144.541.103 ptas.

- De 1820 a 1821: 103.875 .000 ptas.

- De 1822 a 1823: 135.700 .000 ptas.

- De 1824 a 1828: 142.469.564 ptas.

- En 1829: 146.928 .362 ptas.

- En 1830: 130.176 .595 ptas.

- En 1831: 165.382 .654 ptas.

- En 1832: 156.161 .398 ptas.

Por su parte, los importes de los gastos públicos correspondientes a los años que se mencionan fueron los siguientes:

- En 1808: 215.292 .934 ptas.

- En 1810: 178.493 .400 ptas.

- En 1812: 166.203 .331 ptas.

- En 1828: 113.500 .000 ptas.

- En 1832: 112.122 .172 ptas.

Partiendo de los anteriores ingresos y gastos, el control contable realizado por el órgano creado al efecto por el Texto constitucional de Cádiz tuvo su concreto ámbito objetivo de actuación en la fiscalización de los fondos públicos. La delimitación conceptual de estos fondos, como públicos, descansa en los muy numerosos pronunciamientos de la Sala Segunda del Tribunal Supremo sobre este particular, desde los primeros años de su actividad jurisprudencial, precisamente a partir de 1812 .

Puede hacerse mención, como más significativas y como herederas de los primeros pronunciamientos jurisprudenciales desde 1812, de las sentencias del Tribunal Supremo de 8 de mayo de 1873, 19 de marzo de 1874, 12 de diciembre de 1877, 12 de marzo de 1880, 6 de mayo de 1881, 5 de febrero de 1886, 29 de noviembre de 1887, 17 de mayo de 1892, 23 de diciembre de 1896 y 30 de mayo de 1898, de las que se derivan los siguientes extremos:

- Son fondos públicos los de propiedad pública y los que están a cargo de un funcionario público. 
- Tienen este carácter los destinados a servicios públicos.

- Poseen, asimismo, naturaleza pública los fondos que se encuentran bajo la inmediata custodia del Estado.

- Debe entenderse como público cualquier bien perteneciente al patrimonio público, tanto el que haya ingresado de un modo formal en el inventario de los bienes públicos, como los destinados a ingresar en los fondos que tienen carácter público.

- Son públicos los fondos, con independencia de cuál sea el origen de su recaudación, desde el momento en el que ingresan en el haber de un organismo público, para el logro de sus fines y por venir sujetos a normas administrativas de contabilidad y formalizaciones.

- Son igualmente fondos públicos los pertenecientes a cualquier entidad o institución pública y estén afectos a los intereses patrimoniales de carácter público, por lo que la calidad de los bienes públicos se recibe por el destino dado a los mismos.

- Tiene naturaleza jurídica de fondo público todo capital, hacienda, patrimonio, cosa o bien, de cualquier condición, fungible o no, y susceptible de apreciación económica o valor, que pertenezca dominicalmente al erario público, incluidos los bienes particulares, con tal de que intervenga en el acto de depósito o embargo persona pública.

- Han de considerarse como fondos públicos los del Estado y los de entidades públicas cuyo patrimonio o funcionamiento venga fiscalizado públicamente en razón a la finalidad general que cumpla.

- Los fondos cobran naturaleza pública tanto cuando de un modo efectivo pasan a incorporarse al patrimonio público, tras el cumplimiento de las formalidades prescritas, como cuando, percibidos por el funcionario surge en el organismo o ente correspondiente el derecho expectante a su entrega y real ingreso en las arcas públicas.

- Deben considerarse como de naturaleza pública aquellos fondos que, por razones de interés general, forman parte del ámbito de la contratación administrativa.

Después de 1812, la naturaleza de los fondos públicos fue, pues, objeto de significativa evolución, guardando siempre estrecha relación con el carácter objetivo del concepto de cuenta, que iría progresivamente entendiéndose como instrumento contable en el que se reflejan los datos relativos a ingresos y gastos, tomando siempre como referencia un específico período temporal de actividad económico-financiera derivada precisamente de aquellos ingresos y gastos. 


\section{ASPECTOS FORMALES DEL CONTROL DEL GASTO PÚBLICO DESDE 1812}

La principal función de la Contaduría Mayor creada por la Constitución de Cádiz consistió en el control de las cuentas públicas. En el aspecto jurídico-formal, este cometido se vio reforzado a partir del momento en que se refundieron las funciones de la propia Contaduría con las del Tribunal de Cuentas, particularmente a partir del año 1873.

Estaban sujetos a rendición de cuentas los Ministerios, autoridades y funcionarios que tuvieran a su cargo la administración, manejo, recaudación y custodia de caudales, rentas, impuestos, derechos y pertenencias del Estado.

Debía informarse también de los actos ilegales que tanto los ordenadores de pagos como los interventores pudieran realizar en el ejercicio de sus funciones. De la misma manera, debía darse inmediata cuenta de los alcances, desfalcos y malversaciones que los jefes de las dependencias administrativas descubriesen en las mismas.

Así, la Instrucción de 30 de junio de 1820 disponía que, si en el examen de las cuentas la Contaduría encontrase falsedades o defectos de «mala versación» de caudales que indujeran al dolo, la propia Contaduría impondría a los sujetos que hubieren cometido los fraudes «la exacción del tres tanto».

La Real Cédula de 10 de noviembre de 1828, que ha sido objeto de referencia al comienzo del presente estudio, creó en la Contaduría Mayor de Cuentas dos órganos especiales: el llamado «Fiscal de Contabilidad» y el denominado «Fiscal Togado», que era el encargado de actuar cuando la Contaduría ejercía funciones de naturaleza jurisdiccional. Este fiscal asumía las funciones que tanto la legislación procesal posterior a 1812, como la práctica forense de la época, atribuían a los Fiscales de los restantes Tribunales superiores de la Corte.

Además, la mencionada Real Cédula de 1828 reguló la imposición de penas en que incurrían los que, estando obligados a rendir cuentas, no las presentaban en el tiempo prevenido, así como los que las presentaban con defectos no constitutivos de delitos y los que, en último término, cometían defectos en las cuentas constitutivos de verdaderos delitos. Entre estos delitos se hacía referencia a los siguientes:

- Falsificar o alterar sustancialmente los documentos justificativos de las cuentas.

- Suplantar las firmas u otras actuaciones de la misma naturaleza.

- Resultar alcanzado por malversación o abuso de los caudales o efectos de la Real Hacienda. 
Desde 1849, la defensa de los intereses de la Hacienda Pública se encomendó a la Dirección General de lo Contencioso, que se incardinó en el Ministerio de Hacienda mediante Real Decreto de 28 de diciembre de 1849. Tanto esta última disposición, como el Real Decreto de 29 de diciembre de 1854, que crea la Asesoría General del Ministerio de Hacienda, encomendaron a los integrantes de aquella Dirección, primero, y de esta Asesoría General, después, la vigilancia y el cuidado de los intereses de la Hacienda Pública, así como el deber de seguir la correspondencia con los fiscales del Tribunal de Cuentas. Estas disposiciones extendieron su vigencia hasta el 16 de marzo de 1881, fecha en la que se restableció la Dirección General de lo Contencioso del Estado y se creó el Cuerpo de Abogados del Estado.

Por Real Decreto de 16 de marzo de 1886 se distinguieron por primera vez las funciones del Ministerio Fiscal y las de la Abogacía del Estado en los procedimientos en que intervenían simultáneamente ante el Tribunal de Cuentas: el Fiscal actuaba como representante de la Ley, mientras que el Abogado del Estado lo hacía en representación y defensa en juicio de la Hacienda Pública.

Una interesante cuestión que suscita el estudio de los aspectos formales del control del gasto público desde la Constitución de 1812 es la relativa a la compatibilidad de la función fiscalizadora realizada por la Contaduría Mayor de Cuentas - posteriormente llevada a cabo, como se ha dicho, por el Tribunal de Cuentas - con el ejercicio de la jurisdicción ordinaria, por parte de los Tribunales de Justicia, en el control y ulterior exigencia de responsabilidades como consecuencia de una indebida gestión de fondos públicos.

Así, por ejemplo, el artículo 17 del anteriormente mencionado Decreto de 7 de agosto de 1813, que aprobó el Reglamento de la Contaduría Mayor de Cuentas, disponía lo siguiente:

«Si en el examen de las cuentas hecho por la Contaduría Mayor, resultase algún incidente que deba ventilarse en Tribunal de justicia, se decidirá en la Audiencia del distrito donde resida la Contaduría Mayor, y en este caso el Presidente de la Contaduría Mayor nombrará uno de sus individuos para que asista a su vista y determinación con voto consultivo.»

La cuestión apuntada, referente a la compatibilidad entre la jurisdicción de la Contaduría Mayor de Cuentas instaurada con la Constitución gaditana - y, después, la jurisdicción del Tribunal de Cuentas-, con la actuación de los Tribunales de Justicia ordinarios, integrados en el Poder Judicial del Estado, que, en la práctica, sigue a veces presentando actualmente algunas zonas de fricción, fue objeto de tratamiento, con posterioridad al Texto constitucional de Cádiz, de va- 
rias sentencias del Tribunal Supremo de mediados y finales del siglo XIX, conforme se iba consolidando la jurisprudencia más cercana a 1812.

De las expresadas sentencias destacamos la de 12 de diciembre de 1892, cuyos considerandos pueden resumirse en los siguientes razonamientos:

- Los Tribunales de lo contencioso-administrativo tenían preferencia frente a la jurisdicción del Tribunal de Cuentas para conocer de los litigios derivados de la fianza constituida en efectos públicos o valores mobiliarios, cuyos intereses se encontraban afectos para responder de los desfalcos y alcances de los contratistas.

- Si bien correspondía al Tribunal de Cuentas el conocimiento de los expedientes de reintegro en los casos de alcances o desfalcos de caudales públicos descubiertos fuera de los juicios de cuentas, esto debía entenderse en aquellos casos en los que los responsables, por razón del empleo o cargo público conferido, hubiesen intervenido directamente en el manejo de dichos caudales.

- En el caso de autos, ni el contratista era empleado público, ni recibió concesión alguna especial, sino que simplemente contrató en subasta con la Administración la prestación de un servicio público, y como los frutos formaban parte de la prenda y aumentaron por una accesión natural la garantía dada al acreedor, debían aplicarse a la Administración para cubrir el desfalco hasta donde fuese posible, aun cuando los efectos constituidos en fianza pertenecieran a un tercero y no al contratista.

Las responsabilidades derivadas del control de las cuentas públicas se hacían efectivas por la Contaduría Mayor y, posteriormente, por el Tribunal de Cuentas a través de dos procedimientos distintos: en primer lugar, los expedientes de reintegro de alcances y desfalcos; y, en segundo término, los juicios de cuentas.

Debe significarse, por último, que la principal diferencia formal de estos cauces para la exigencia de responsabilidades contables consistía en el hecho de que se tuviera conocimiento de la correspondiente irregularidad contable fuera del examen de la respectiva cuenta o, en otro caso, como consecuencia precisamente del examen y comprobación de la cuenta en cuestión.

A partir de la Ley de 25 de agosto de 1851 y del Reglamento de 2 de septiembre de 1853, los juicios de cuentas constaban de las siguientes fases:

- Examen de las cuentas.

- Censura de las mismas.

- Pliego de reparos.

- Emplazamientos de las personas y entidades afectadas. 
- Contestación de los interesados.

- Dictamen del Fiscal.

- Vista y calificación de las cuentas.

- Decisión final motivada.

Contra esta última decisión podía interponerse ante la Sala del Tribunal de Cuentas los recursos de aclaración, nulidad y revisión. Y cabía, finalmente, la posibilidad de promover recurso de casación, del que conocía el Consejo Real.

\section{CONSIDERACIONES FINALES}

En lo que al ámbito de nuestro estudio se refiere, la Constitución de Cádiz merece una crítica ciertamente positiva por la sola circunstancia de elevar a rango constitucional el control del gasto público, con todo lo que ello significa y representa. Como se ha dicho autorizadamente, el control del gasto público constituye requisito ineludible y fundamental en el funcionamiento y la actuación de las sociedades democráticas.

No resulta exagerado afirmar que, a partir del texto constitucional gaditano, se produjo un intento, ciertamente limitado y en algunas ocasiones difuso, de reforzar la independencia del Tribunal de Cuentas con respecto al Poder Ejecutivo; al mismo tiempo, de estrechar las relaciones funcionales del propio Tribunal con el Legislativo y, en cierto aspecto, de articular y delimitar sus funciones de contenido jurisdiccional, en lo que a la exigencia de responsabilidades contables se refiere.

Desde la creación de la Contaduría Mayor de Cuentas en 1812, la lucha contra la corrupción fue objeto de diferente y variado tratamiento, particularmente en la administración, manejo y utilización de los fondos públicos. Y ello sin olvidar que el fenómeno de la corrupción no fue exclusivo ni de esta época, ni de países como el nuestro. Ya en la antigua Grecia — hace veinticinco siglos- se contraponían dos términos en la organización del sistema político: la ética y la política, siendo Aristóteles quien por primera vez diseñó el discurso moral, y ello sin olvidar que Platón perfiló en sus Diálogos la base de lo que posteriormente conoceríamos con el nombre de «ética». Por lo demás, la concepción ética del poder constituye un principio deontológico desencadenante del proceso de construcción y diseño institucional de la modernidad.

La corrupción es, pues, un fenómeno que todavía sigue vigente y que se ha extendido a diferentes países como consecuencia de una progresiva crisis de valores. Se debe a un abuso de poder en la toma de decisiones y comprende, como ha puntualizado el Consejo de Europa, «las comisiones ocultas y cualquier ac- 
tuación que personas investidas de funciones públicas llevan a cabo con violación de sus deberes para obtener ventajas ilícitas, ya para sí ya para terceros».

Ante este fenómeno se hace precisa la defensa del Estado mediante diversos procedimientos, que deben articularse según los motivos que explican su presencia en las sociedades democráticas. Estos motivos pueden ser generales - la crisis de valores, que repercute en la integración social que mantiene vivas a las sociedades-; políticos — pérdida de fe en el Estado y en el poder político, y ausencia de confianza en los valores legales y sociales que lo legitiman-; económicos - el espíritu de competencia desmesurado y el enriquecimiento sin límite-y sociales, pues el culto al consumo fomenta inevitablemente la atomización social.

La corrupción supone, pues, un peligro para las sociedades, que puede paliarse con la educación y la reflexión moral, por medio de la ética pública y la acción del Derecho, que tiene un elemento inicial o primario: la idea de ética como componente moral del Derecho, y un elemento final o teleológico: la idea de Justicia como resultado aplicativo del Derecho.

Como se ha podido comprobar a lo largo del presente trabajo, entre los principales mecanismos contra la corrupción está el control de la gestión de los fondos públicos, en donde el Tribunal de Cuentas adquiere especial relevancia.

Nuestra Constitución de 1978 dispone en el artículo 136 que «es el supremo órgano fiscalizador de las cuentas, de la gestión económica del Estado y del sector público». El artículo 2 de su Ley Orgánica indica que la actividad fiscalizadora del Tribunal es una función externa de control, independiente del ente fiscalizador; permanente, sin limitación temporal en cuanto a su ejecución; y, por último, consuntiva, es decir, a posteriori o ex post facto, ya que se realiza una vez producido el gasto.

La importancia del Tribunal de Cuentas en la defensa de una adecuada gestión de los fondos públicos resulta, pues, incuestionable. La finalidad de los procedimientos fiscalizadores del Tribunal, según el artículo 9 de dicha Ley Orgánica, consiste en el sometimiento de la actividad económica del sector público a los principios de legalidad, eficiencia y economía.

Además, el mencionado artículo 136.2 contempla una «jurisdicción propia» del Tribunal, verdadera jurisdicción al atribuirse a la Sala Tercera del Tribunal Supremo el conocimiento de los recursos de casación contra sentencias del Tribunal de Cuentas. El Juez de lo contable asume así el control jurisdiccional de la gestión pública en lo económico y presupuestario, dentro de lo que supone la «jurisdicción del gasto público», y representa el Juez natural predeterminado por la Ley para conocer de las acciones públicas contables y revisar actuaciones de los gestores públicos que ocasionen un perjuicio patrimonial en los fondos públicos: malversaciones, pagos indebidos y administrar los recursos de la Hacienda pú- 
blica, comprometer gastos y ordenar pagos con infracción de la Ley General Presupuestaria.

La Sala de Justicia del Tribunal de Cuentas, en una clarificadora sentencia de 30 de junio de 1992, señaló los requisitos para que una acción constituya responsabilidad contable: «a) Que sea atribuible a una persona que tenga a su cargo caudales públicos; b) Que se desprenda de las cuentas que deben rendir quienes administren aquellos caudales; c) Que vulnere la normativa presupuestaria del sector público; $d$ ) Que produzca un menoscabo en dichos caudales por dolo, culpa o negligencia grave; $e$ ) Que este menoscabo sea efectivo, individualizado y evaluable económicamente y f) Que exista una relación de causalidad entre aquella acción y el daño producido».

La responsabilidad contable afecta, en definitiva, a una indebida gestión de fondos públicos. Por ello, cualquier delito, además de las malversaciones, que produzca perjuicios económicos en las haciendas públicas — como los de fraude de subvenciones, prevaricación urbanística, estafa, falsificación de documentos públicos, tráfico de influencias, uso de información privilegiada, exacciones ilegales y, en general, los relacionados con el despilfarro y la corrupción en el ámbito público, en extremos como la contratación administrativa, la concesión de subvenciones y de licencias, y la gestión urbanística y medioambiental- debe comunicarse al Tribunal de Cuentas, en cumplimiento de los artículos 18 de su Ley Orgánica y 49 de su Ley de Funcionamiento. Y, finalmente, todas las resoluciones de las distintas Administraciones Públicas que declaren responsabilidades contables — por ejemplo, en materia de subvenciones, pagos indebidos y gastos ilegales — deben ser recurribles ante la Sala de Justicia del Tribunal de Cuentas, en aplicación del artículo 41 de la ciada Ley Orgánica.

La contribución de la Constitución de Cádiz al control de las cuentas públicas fue, pues, decisiva: tanto la Contaduría Mayor de Cuentas, con relevancia constitucional desde 1812, como el Tribunal de Cuentas, en sus posteriores y sucesivas regulaciones, hasta llegar a la más destacada de nuestros días contenida en el artículo 136 de la vigente Constitución —una de las instituciones con mayor tradición y significación histórica-, representan el progresivo y constante interés de los constituyentes en dotar al gasto público, en general, y a la gestión económico-financiera del sector público, en particular, de un adecuado y eficiente sistema de control y fiscalización y, en fin, de regular un proceso eficaz, con todas las garantías constitucionales y legales, para la exigencia de responsabilidades contables en que pueden incurrir los gestores públicos. 


\section{BIBLIOGRAFÍA BÁSICA SOBRE EL TRIBUNAL DE CUENTAS}

Ariel Rezzongli, B.: Corrupción y contratos públicos. Una visión desde la fiscalización del Tribunal de Cuentas, Salamanca, 2005.

Cazorla Prieto, L. M.: El control de las Corporaciones Locales por el Tribunal de Cuentas, Instituto de Estudios de Administración Local, Madrid, 1982.

Del Cacho F. Rago, A.: Tribunal de Cuentas. Legislación estatal y autonómica sobre la fiscalización económico-financiera de las Administraciones Públicas y de las entidades del sector público. Conclusiones y comentarios jurisprudenciales —en colaboración con EsCUSOl Barra, E.-, Madrid, 1997.

Cubillo Rodríguez, C.: La jurisdicción del Tribunal de Cuentas, Granada, 1999.

Fanlo Loras, A.: El Tribunal de Cuentas y las Corporaciones Locales, Instituto de Estudios de Administración Local, Madrid, 1986.

Fernández Pirla, J. M.: Una aportación a la construcción del Derecho Contable, Madrid, 1986.

Fernández Pirla, J. M.: El Tribunal de Cuentas, ayer y hoy, Madrid, 1987.

Galán SÁnchez, R. M.: El enjuiciamiento contable. El control de la gestión de fondos públicos por el Tribunal de Cuentas, Instituto de Estudios Fiscales, Madrid, 2001.

García García, J. L.: El Control (externo e interno) en la Constitución; Instituto de Estudios Fiscales, Madrid, 1979.

Gómez SÁNCHEZ, Y.: El Tribunal de Cuentas. El control económico-financiero externo en el ordenamiento constitucional español, Madrid, 2001.

GonZalo y GonZÁlez, L.: El Sector Público en España. El sujeto y el campo de la actividad financiera pública. Régimen presupuestario de las Administraciones Públicas, Madrid, 2005.

Jiménez Rius, P.: El control de los fondos públicos. Propuestas de mejora, Cizur Menor (Navarra), 2007.

López Castellano, F.: «La contabilidad pública en las Cortes de Cádiz: la 231 "Memoria sobre las Cuenta y Razón de España” (1811), de José Canga Argüelles», en Revista Española de Historia de la Contabilidad, núm. 10, junio de 2009.

Martínez Alcubilla, M.: Diccionario de la Administración Española. Compilación de la Novísima Legislación de España en todos los ramos de la Administración Pública, tomo IV, Madrid, 1915 y tomo VIII, Madrid, 1919.

Nieto de Alba, U.: El control en el sector financiero, Madrid, 1989.

Pascual García, J.: Régimen Jurídico de las subvenciones públicas, Madrid, 1996.

- Régimen Jurídico del gasto público: presupuestación, ejecución y control, Madrid, 1999.

Piernas Hurtado, J.: Tratado de Hacienda Pública y Examen de la Española, Madrid, 1901.

RosiÑol VIDAL, C.: La responsabilidad contable y la gestión de los recursos públicos, Madrid, 1994. 
Ruíz TARrías, S.: La función jurisdiccional de los Órganos de Control Externo. Especial referencia a la Cámara de Cuentas de Andalucía, Madrid, 2003.

SALA SÁnCHEZ, P.: La jurisdicción contable: las responsabilidades contables y su enjuiciamiento en la nueva Ley Orgánica del Tribunal de Cuentas de España, Madrid, 1984.

Sala SÁnchez, P. y Martínez Noval, L. (directores): El Tribunal de Cuentas: fiscalización y enjuiciamiento, Consejo General del Poder Judicial, Madrid, 2004.

SuÁrez SuÁrez, A. S.: El control o fiscalización del sector público. Auditorías de eficiencia, Madrid, 1986.

VACAs GarcíA-Alós, L.: El Tribunal de Cuentas: enjuiciamiento contable y jurisprudencia constitucional, Madrid, 1998.

- La responsabilidad contable de los gestores públicos y de los perceptores de subvenciones en la jurisprudencia, Madrid, 2009.

Vacas García-Alós, L. y Gutiérrez García, C. (directores): El Tribunal de Cuentas: fiscalización y enjuiciamiento, Consejo General del Poder Judicial, Madrid, 2006.

VaCas García-Alós, L. y Martín Martín, G.: Comentarios a la Ley Orgánica del Poder Judicial, Cizur Menor (Navarra), 2008.

VV.AA.: El Tribunal de Cuentas en España, Instituto de Estudios Fiscales, Madrid, 1982.

Title:

THE INFLUENCE OF THE CONSTITUTION OF 1812 IN THE CONTROL OF THE PUBLIC ACCOUNTS

\section{Summary:}

1. THE ANTECEDENTS OF THE NATIONAL AUDIT OFFICE AND THE CONSTITUTIONAL REGULATION OF THE CONTROL OF THE PUBLIC ACCOUNTS IN THE 1812 CONSTITUTION. 2. SUBJECTIVE ASPECTS OF THE COUNTABLE CONTROL IN THE CONSTITUTIONAL TEXT OF CADIZ. 3. OBJECTIVE ASPECTS OF THE CONTROL OF THE PUBLIC ACCOUNTS FROM CONSTITUTIONAL NORM OF CADIZ. 4. FORMAL ASPECTS OF THE CONTROL OF THE PUBLIC COST FROM 1812. 5. FINAL CONSIDERATIONS. 6. BASIC BIBLIOGRAPHY ON THE NATIONAL AUDIT OFFICE.

\section{Resumen:}

El artículo examina la evolución del régimen jurídico-normativo del control de las cuentas públicas a lo largo del siglo XIX, principiando por la fundamental aportación de la Constitución de Cádiz de 1812, que elevó a rango constitucional el control del gasto público con la 
creación de la Contaduría Mayor. La tarea fiscalizadora de las cuentas públicas fue perfilándose progresivamente en torno a la figura del cuentadante y se vio reforzada con la refundición de las funciones de la Contaduría Mayor con las del Tribunal de Cuentas el 23 de mayo de 1873.

\section{Abstract:}

The article examines the evolution of the legal-normative regime of the control of the public accounts throughout century XIX, beginning by the fundamental contribution of the Constitution of Cadiz of 1812, that elevated to constitutional rank the control of the public cost with the creation of the Greater Accountant's office. The supervise task of the public accounts was being outlined progressively around the figure of the cuentadante and it was reinforced with the reworking of the functions of the Greater Accountant's office with those of the $\mathrm{Na}$ tional Audit Office on the 23 of May of 1873.

Palabras clave:

Cuentas públicas, gasto público, cuentadante, Contaduría Mayor, Tribunal de Cuentas.

Key words:

Public accounts, public cost, Greater Accountant's office, National Audit Office. 
